\title{
Doença Autoimune do Ouvido Interno: Revisão da Literatura
}

\section{Autoimmune Inner Ear Disease: Literature Review}

Margarida Branco ${ }^{1}$, Cristina Caroça $a^{1,2}$, Paula Campelo ${ }^{1}$,

Catarina Tinoco ${ }^{1}$, Maria Caçador ${ }^{1,2}$, João Paço ${ }^{1,2}$

Autor Correspondente: Margarida Branco [margarida_s.b@hotmail.com]

\section{RESUMO}

A surdez autoimune é uma entidade clínica rara, representando geralmente um desafio diagnóstico, correspondendo muitas vezes à manifestação inicial de um distúrbio autoimune sistémico.

Caracteriza-se pela presença de hipoacusia neurossensorial, bilateral e assimétrica de instalação progressiva durante semanas a meses. Em 50\% dos casos, associado à surdez, verifica-se a presença de sintomas vestibulares, acufenos ou plenitude auricular. Dada a ausência de testes específicos que permitam a realização de um diagnóstico definitivo, este é baseado na suspeita clínica e na resposta ao tratamento com terapia imunossupressora.

O diagnóstico diferencial é realizado através de uma história clínica detalhada com exame objetivo completo, bem como exames audiométricos, laboratoriais e imagiológicos de modo a excluir outras etiologias de surdez neurossensorial.

A raridade desta doença, o grande espectro de manifestações clínicas, a ausência de estudos randomizados que demonstrem a eficácia do tratamento, bem como a ausência de resultados a longo prazo, fazem desta doença um desafio.

Com este artigo os autores pretendem realizar uma revisão do tema de modo a facilitar a identificação precoce desta patologia e permitir a instituição adequada de tratamento.

PALAVRAS-CHAVE: Doença Autoimune; Imunossupressores; Surdez Neurossensorial

1. Serviço Universitário de Otorrinolaringologia, Hospital CUF Infante Santo, Lisboa, Portugal. 2. Nova Medical School, Faculdade de Ciências Médicas, Universidade Nova de Lisboa, Lisboa, Portugal.

Recebido: 19/05/2016 - Aceite: 02/06/2016 


\section{ABSTRACT}

Autoimmune hearing loss is a rare clinical entity usually representing a challenge diagnosis, corresponding often to the initial manifestation of a systemic autoimmune disease.

It is characterized by the presence of sensorineural hearing loss, bilateral or asymmetrical, usually of progressive installation for weeks to months. In 50\% of the cases associated with hearing loss, there is vestibular symptoms, tinnitus or ear fullness. Given the absence of specific tests that allow the definitive diagnosis, this is based on clinical suspicion and response to treatment with immunosuppressive therapy.

The differential diagnosis is made through a detailed medical history with complete objective examination, as well as audiometric, laboratory and imaging tests to exclude other sensorineural hearing loss etiologies.

The rarity of the disease, wide spectrum of clinical manifestations, absence of randomized studies that demonstrate the efficacy of the treatment and absence of long-term results of this disease are a challenge.

With this article the authors intend to carry out a review of the topic in order to facilitate the early identification of this condition and allow proper institution of treatment.

KEYWORDS: Autoimmune Diseases; Hearing Loss, Sensorineural; Immunosuppressive Agents

\section{INTRODUÇÃO}

A primeira descrição da surdez autoimune data de 1979, tendo sido realizada por McCabe., ${ }^{1,2}$ Caracteriza-se pela presença de surdez neurossensorial, flutuante, geralmente bilateral e assimétrica, de instalação progressiva durante semanas ou meses e com resposta ao tratamento imunossupressor. ${ }^{3}$ Esta premissa faz com que seja uma das poucas formas de hipoacusia neurossensorial potencialmente reversível após tratamento médico. 1,4,5

Só na década de cinquenta é que a sociedade científica admitiu o conceito de autoimunidade. Apesar da etiologia da doença autoimune do ouvido interno (DAIOI) ainda não ser completamente conhecida, foram propostos múltiplos mecanismos para explicar a etiopatogenia da mesma. ${ }^{1,3}$

Existem no entanto, algumas patologias que não sendo a surdez autoimune como definida, apresentam uma possível etiologia autoimune: surdez súbita, surdez rapidamente progressiva e a doença de Ménière. Em alguns casos a surdez autoimune pode surgir associada a doença sistémica, tal como: síndrome de Cogan, poliartrite nodosa, lúpus eritematoso sistémico, artrite reumatoide, síndrome de Sjögren, entre outras.

\section{EPIDEMIOLOGIA}

A incidência da surdez autoimune não é verdadeiramente conhecida dada a ausência de um teste diagnóstico definitivo. No entanto, a literatura refere uma incidência estimada de cerca de 1:5000 - 10 000/ano, representando incidência inferior à da surdez súbita. É mais frequente no sexo feminino, tal como a generalidade das doenças autoimunes. É rara na infância, apresentando um pico entre os 20 e 50 anos. ${ }^{1-4}$

\section{ETIOPATOGENIA}

A etiologia da surdez autoimune é desconhecida., ${ }^{1,4}$ Dada a impossibilidade de realizar biópsia do ouvido interno no ser humano, para o estabelecimento de um diagnóstico definitivo, têm sido utilizados modelos animais para estudo desta patologia.

Várias teorias têm sido propostas para explicar o surgimento desta doença.

Quer a imunidade inata quer o sistema imune adaptativo estão implicados na etiopatogenia desta entidade, sendo responsáveis pelas alterações histológicas observadas na cóclea de doentes com doença autoimune do ouvido interno (DAIOI). Estas incluem lesão do órgão de Corti, degeneração neural, hidrópsia endolinfática, lesão da estria vascular, osteogénese e fibrose da espira basal da cóclea, fibrose do saco endolinfático e a presença de linfócitos no labirinto membranoso. ${ }^{5}$

Segundo para alguns autores, um ataque imunomediado seria responsável pelas alterações verificadas na cóclea dos doentes com DAIOI. ${ }^{6}$

Estudos realizados em animais mostraram a presença de auto-anticorpos e células T contra antigénios vestíbulo-cocleares. Por sua vez, trabalhos realizados em seres humanos revelaram a presença de complexos imunes em doentes com DAIOI, e que a corticoterapia estava associada à melhoria dos níveis audiométricos e à eliminação desses complexos imunes. ${ }^{5,6}$

Existem no entanto algumas patologias que podem apresentar uma etiologia autoimune: a surdez súbita, a surdez rapidamente progressiva e a doença de Ménière.

O papel do sistema imune na etiologia da surdez súbita 
idiopática, bem como, na etiologia de patologia vestibular, foi introduzido no início do século passado. Em 1979, McCabe descreveu doentes com surdez bilateral progressiva que respondiam ao tratamento com corticoides. A apresentação clínica da surdez neurossensorial pode ser bastante diversa, podendo mesmo ser semeIhante a outras patologias, tal como, a doença de Ménière. Hughes et al reportaram que 52\% dos doentes com o diagnóstico de doença autoimune do ouvido interno apresentavam sintomas otológicos e vestibulares, levantando assim a hipótese da existência de um continuum entre DAIOI e a doença de Ménière?

\section{MANIFESTAÇÕES CLÍNICAS}

A surdez autoimune pode manifestar-se como doença isolada do ouvido interno ou como parte do quadro de uma doença autoimune sistémica. ${ }^{1-3}$ Habitualmente, apresenta-se como hipoacusia neurossensorial, unilateral ou bilateral assimétrica, com instalação progressiva

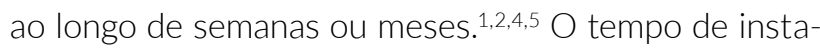
lação é um dos fatores mais importantes para o diagnóstico. Apesar de 50\% dos doentes reportar surdez unilateral, verifica-se a presença de surdez bilateral e assimétrica em 80-100\% das situações ${ }^{3}$ (após realização de exames audiométricos). A flutuação dos níveis audiométricos é frequente. ${ }^{3}$ Em cerca de 50 a $80 \%$ dos casos coexistem sintomas vestibulares, nomeadamente, vertigem ou desequilíbrio. ${ }^{3}$ A presença de acufenos é variável, surgindo em 25 a 50\% dos doentes, assim como, sensação de plenitude auricular em igual percentagem. ${ }^{3}$ Cerca de um terço dos casos ocorre no contexto de doenças autoimunes sistémicas, podendo corresponder à sua primeira manifestação, de que são exemplos a granulomatose de Wegener, o lúpus eritematoso sistémico (LES), a poliartrite nodosa, a artrite reumatoide, a síndrome de Sjogrën, a síndrome de Cogan, entre outras. ${ }^{2,3}$

\section{DIAGNÓSTICO}

O diagnóstico precoce desta entidade, assim como a instituição imediata de tratamento agressivo é crucial para o prognóstico. ${ }^{1}$

O diagnóstico desta entidade baseia-se na história clínica, na demonstração através de exames audiométricos de surdez neurossensorial progressiva e na resposta ao tratamento com terapia imunossupressora, nomeadamente os corticoides. , $^{1,4}$

A história clínica permite avaliar determinadas características, nomeadamente o tempo de instalação da hipoacusia, sintomas otológicos concomitantes e fatores predisponentes (exposição a ruído, quimioterapia ou tratamento prévio com antibióticos ototóxicos, cirurgia otológica prévia, história de trauma, meningite ou história familiar de surdez). 1,4,8

Por vezes, o diagnóstico diferencial com surdez súbita pode ser desafiante. Enquanto a DAIOI é frequentemente bilateral e apresenta uma progressão durante semanas a meses, a surdez súbita é geralmente unilateral e desenvolve-se num período inferior ou igual a setenta e duas horas. ${ }^{4}$

É importante, ainda, excluir outras entidades que possam mimetizar a DAIOI, incluindo esclerose múltipla, neoplasias e sífilis. ${ }^{1}$

Após exclusão de outras etiologias de surdez neurossensorial devem ser realizados exames laboratoriais comuns a todas as doenças autoimunes, tais como: hemograma, bioquímica sanguínea, velocidade de sedimentação, entre outras. ${ }^{1}$ Apesar de atualmente não existir nenhum exame com sensibilidade e especificidade suficiente para estabelecimento do diagnóstico definitivo, a avaliação serológica permite identificar auto-anticorpos específicos e não-específicos. ${ }^{1,4}$

A deteção de auto-anticorpos permite reconhecer a natureza autoimune desta entidade, mas a sua identificação não permite o estabelecimento de um diagnóstico definitivo, dada a ausência de especificidade dos mesmos. ${ }^{1}$ Ao longo dos últimos anos, ${ }^{6}$ múltiplos exames têm sido propostos para auxiliar o diagnóstico, mais precisamente pesquisa de auto-anticorpos contra o colagénio tipo II, contra células endoteliais e contra glicofosfolípidos, entre outros. Os auto-anticorpos contra o colagénio tipo II são detetados em inúmeras patologias que afetam o ouvido interno e ainda, segundo alguns autores, permitem prever a resposta ao tratamento imunossupressor.?

TABELA 1. Auto-anticorpos na doença autoimune do ouvido interno.

DAIOI - Auto-anticorpos Específicos e Não-específicos ${ }^{1}$

\section{Auto-anticorpos Específicos}

Colagénio tipo II

Colagénio tipo IX

DEP-1/CD 148

Proteína mielínica PO

KHRI-3

Raf-1

Beta-tectorina

Conexina 26

\section{Auto-anticorpos não-específicos}

Anticorpos antinucleares

Anticorpo anti-citoplasma neutrófilos (ANCA)

Anticorpo anti-célula endotelial

Fator reumatoide (FR)

HSP 70 (heat shock protein 70)

Anticorpo anti-fosfolípido/anti-cardiolipina

Anticorpo anti-tiroideus 
Na Tabela 1 é possível observar um conjunto de auto-anticorpos (específicos e não-específicos) presentes em indivíduos com DAIOI. ${ }^{1}$

Harris and Sharp foram os primeiros a propor a técnica de Western Blot para a pesquisa de auto-anticorpos contra antigénios do ouvido interno, ${ }^{10}$ sendo o anticorpo anti-HSP 70 (heat shock protein 70) o mais estudado na literatura científica. Esta proteína é expressa numa grande variedade de patologias que afetam o ouvido interno.

Contudo, alguns autores afirmam que a pesquisa deste anticorpo não apresenta utilidade clínica, uma vez que este é igualmente expresso nos indivíduos com DAIOI e na população em geral. ${ }^{10}$ Outros trabalhos demonstraram que este não está diretamente relacionado com a patogénese de DAIOI, contudo afirmam que pode ser um marcador de atividade da doença. ${ }^{10}$

Segundo Gottschlich et al, ${ }^{11}$ este método apresenta uma sensibilidade de $22 \%$. No que diz respeito à especificidade, também é alvo de controvérsia. Cerca de 5\% da população saudável e 33\% dos doentes com Ménière apresentam anticorpos contra a proteína $\mathrm{Kd}$-68.11

De acordo com alguns autores, a autoimunidade parece ser responsável por 6\% dos casos de surdez unilateral e $16 \%$ dos casos de surdez bilateral na doença de Ménière. Desde longa data que se suspeita que a doença de Ménière possa apresentar uma etiologia imunomediada ou mesmo ser autoimune. Múltiplos parâmetros laboratoriais, tais como, HSP 70, TNF, ANA, VS estão relacionados com a autoimunidade na doença de Ménière. Por outro lado, é uma patologia em que a corticoterapia faz parte do tratamento. Sendo de salientar que o diagnóstico da doença autoimune do ouvido interno ainda é baseado na resposta ao tratamento imunosupressor.?

Contrariamente aos resultados promissores iniciais, nem a ressonância magnética (RM), nem a tomografia por emissão de positrões (PET) são úteis no diagnóstico de DAOIO. ${ }^{1}$

Alguns autores propuseram um conjunto de critérios clínicos para o diagnóstico de surdez autoimune (Tabela 2). Segundo os mesmos, o diagnóstico de DAIOI deve ser realizado na presença de três critérios major ou na presença de dois critérios major e dois critérios minor. ${ }^{1}$

\section{TRATAMENTO}

Desde a primeira descrição em 1979 por McCabe, a corticoterapia tem sido a base do tratamento desta entidade devido às suas propriedades imunossupressoras e aos seus efeitos na modulação do transporte iónico. ${ }^{1}$
TABELA 2. Critérios de diagnóstico de doença autoimune do ouvido interno. ${ }^{1}$

\begin{tabular}{l} 
Critérios de diagnóstico de doença autoimune \\
do ouvido interno \\
Critérios major \\
Hipoacusia bilateral \\
Doença autoimune sistémica \\
ANA $>1: 80$ \\
Redução de células T nativas (CD4 CD25RA) \\
Taxa de recuperação da audição > 80\% \\
\hline Critérios minor \\
Hipoacusia unilateral \\
Sexo feminino \\
Adolescentes ou jovens adultos \\
Taxa de recuperação <80\%
\end{tabular}

O regime mais largamente utilizado tem como base o tratamento proposto por Rauch et al; preconiza-se uma dose inicial de 60 mg ou $1 \mathrm{mg} / \mathrm{kg} /$ dia de prednisona ou metilprednisolona, que deverá ser mantida durante um mês. ${ }^{1}$ Doses inferiores ou cursos mais curtos são ineficazes e estão associados a elevado risco de recorrência. ${ }^{12}$ Após estabilização dos níveis audiométricos deverá ser realizada uma redução progressiva de corticoterapia durante 8 semanas até alcançar $10-20$ mg/dia, as quais deverão ser mantidas durante mais 6 semanas. ${ }^{1}$

No entanto, nem todos os doentes têm uma resposta eficaz à terapêutica. Segundo alguns autores, a resposta global à terapia com corticoides ronda os 60\%, ${ }^{1}$ contudo esta é extremamente variável.

Por este motivo, novos fármacos imunossupressores têm sido introduzidos no tratamento desta entidade, de que são exemplo o metotrexato e a ciclofosfamida. Com o objetivo de potenciar o efeito da corticoterapia, estes fármacos permitem uma remissão sintomática mais eficaz, assim como uma redução da dose necessária para atingir remissão clínica da doença., ${ }^{1,4}$

Nos doentes com boa resposta à terapêutica é possível reduzir progressivamente a dose até à sua suspensão sem recorrência da surdez. Nos casos em que não é possível suspender o tratamento com corticoides, devem ser instituídos outros fármacos imunossupressores. ${ }^{1}$

Relativamente ao metotrexato, meta-análises mostraram que não existe benefício significativo face à corticoterapia. ${ }^{13}$ Contudo, existem alguns estudos que mostraram uma melhoria da vertigem e a instabilidade. ${ }^{13} \mathrm{O}$ regime mais frequentemente aplicado consiste na administração semanal de 7,5 mg do fármaco por via endovenosa. Após obtenção de resposta audiométrica, o fármaco deverá ser administrado por via oral na dose de

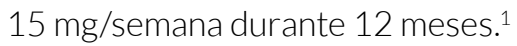


No que respeita à ciclofosfamida, devido aos seus efeitos tóxicos, o seu uso é limitado aos doentes que não respondem aos corticoides e nos casos recrudescentes. ${ }^{1}$ O tratamento mais frequentemente aplicado passa pela administração oral de 1-2 mg/kg/dia durante um período que varia entre 4 a 6 semanas. ${ }^{1}$

\section{Plasmaferese}

Um estudo de 1997 revelou que a plasmaferese permitiu uma melhoria ou estabilização dos níveis audiométricos em 50\% dos doentes. ${ }^{1,14}$

No entanto, os dados atualmente disponíveis sobre esta modalidade terapêutica são escassos.

Luetje et $a^{14}$ avaliam 16 doentes com surdez autoimune e documentaram uma melhoria ou manutenção dos níveis audiométricos em cerca de 39\% dos doentes.

De salientar que o papel da plasmaferese na doença autoimune e a sua relação com o sistema imunitário ainda não se encontra estabelecido.

\section{Implantes Cocleares}

Um subgrupo de doentes com DAIOI que desenvolvem surdez profunda bilateral sem benefício com as próteses convencionais podem ser candidatos a cirurgia de implante coclear. Estudos têm demonstrado alta taxa de sucesso após implante neste subgrupo de doentes. ${ }^{1}$

\section{CONCLUSÃO}

Com este trabalho os autores pretendem alertar para a natureza progressiva da doença autoimune do ouvido interno. Devido à natureza rapidamente progressiva e às lesões irreversíveis associadas, o diagnóstico precoce é imprescindível, sendo de crucial importância a instituição de terapêutica precoce.

A terapia imunossupressora é a base do tratamento desta patologia, sendo uma das poucas etiologias de surdez neurossensorial com tratamento médico eficaz.

Na prática clínica, ainda não é possível estabelecer um diagnóstico definitivo dada a ausência de testes com sensibilidade e especificidade suficiente, tornando esta entidade um desafio diagnóstico.

Mais estudos são necessários para compreender completamente a etiopatogenia da doença autoimune, de modo a melhorar o prognóstico da doença.
CONFLITOS DE INTERESSE: Os autores declaram a inexistência de conflitos de interesse na realização do presente trabalho.

FONTES DE FINANCIAMENTO: Não existiram fontes externas de financiamento para a realização deste artigo.

\section{REFERÊNCIAS}

1. Lobo DR, García-Berrocal JR, Ramírez-Camacho R. New prospects in the diagnosis and treatment of immune-mediated inner ear disease. World J Methodol. 2014 26;4:91-8.

2. Garcia-Berrocal JR, Trinidad A, Ramirez-Camacho R, Lobo D, Verdaguer M, Ibanez A. Immunologic work-up study for inner ear disorders: looking for a rational strategy. Acta Otolaryngol. 2005;125:814-8.

3. Bovo R, Ciorba A, Martini A. The diagnosis of autoimmune inner ear disease: evidence and critical pitfalls. Eur Arch Oto-Rhino-Laryngol. 2008;266:37-40.

4. Mathews J, Kumar BN. Autoimmune sensorineural hearing loss. Clin Otolaryngol Allied Sci. 2003;28:479-88.

5. Goodall AF, Siddiq MA. Current understanding of the pathogenesis of autoimmune inner ear disease: a review. Clin Otolaryngol. 2015;40:412-9.

6. Plester D, Soliman AM. Autoimmune hearing loss. Am J Otol.; 1989;10:188-92

7. Bovo R, Ciorba A, Martini A. Vertigo and autoimmunity. Eur Arch Otorhinolaryngol. 2010;267:13-9.

8. Roland JT. Autoimmune inner ear disease. Curr Rheumatol Rep.; 2000;2:171-4.

9. Helfgott SM, Mosciscki RA, San Martin J, Lorenzo C, Kieval R, McKenna M, et al. Correlation between antibodies to type II collagen and treatment outcome in bilateral progressive sensorineural hearing loss. Lancet. 1991;337:387-9.

10. Harris JP, Sharp PA. Inner ear autoantibodies in patients with rapidly progressive sensorineural hearing loss. Laryngoscope. 1990;100:516-24.

11. Gottschlich S, Billings PB, Keithley EM, Weisman MH, Harris JP. Assessment of serum antibodies in patients with rapidly progressive sensorineural hearing loss and Meniere's disease. Laryngoscope. 1995;105:1347-52.

12. Ryan AF, Harris JP, Keithley EM. Immune-mediated hearing loss: basic mechanisms and options for therapy. Acta Otolaryngol Suppl. 2002;548:38-43.

13. Harris JP, Weisman MH, Derebery JM, Espeland MA, Gantz BJ, Gulya AJ, et al. Treatment of corticosteroid-responsive autoimmune inner ear disease with methotrexate: a randomized controlled trial. JAMA. 2003;290:1875-83.

14. Luetje CM, Berliner KI. Plasmapheresis in autoimmune inner ear disease: long-term follow-up. Am J Otol. 1997;18:572-6. 